\title{
Coulometric Determination of Hydrogen Cyanide in Cigarette Smoke*
}

\author{
by Cephas H. Sloan \\ Research Laboratories, Tennessee Eastman Company, Division of Eastman Kodak Company, \\ Kingsport, Tennessee, U.S.A.
}

\section{INTRODUCTION}

Several methods $(1-5)$ have been developed for the determination of hydrogen cyanide (HCN) in cigarette smoke. These methods, which include the use of colorimetry, ion-selective electrodes, titration, and gas chromatography, can be classified as non-coulometric. All have certain disadvantages.

Colorimetric determinations of $\mathrm{HCN}$ are usually based on a König synthesis, wherein the reaction of cyanogen bromide or chloride with pyridine and an aromatic amine to form a dye involves the use of multi-stage processes and several reagents. Ion-selective cyanide electrodes, described by Vickroy and Grant (3), proved to be unreliable in our laboratory, especially for analyzing wholesmoke solutions that adsorb onto the electrode and cause erratic results.

Mattina (1) described a potentiometric titration for cyanide and sulfide in cigarette smoke. He collected the two components on Ascarite absorbent and performed a potentiometric titration with a standard silver nitrate solution. The plotted data gave two equivalence points, representing sulfide and cyanide. Evaluations of this method have shown that the Ascarite material contains a titratable impurity that gives an end point at the same potential as the sulfide. The titration requires several minutes to complete, and additional time is required for plotting the data and locating the end points.

Brunnemann (2) used a gas diromatographic method based on the conversion of $\mathrm{HCN}$ to cyanogen dhloride with chloramine- $T$. The cyanogen chloride was extracted into hexane and analyzed by using a gas dhromatograph equipped with an electron-capture detector. This method is lengthier and more sophisticated than needed for routine use.

In 1958 Przybylowicz (6) developed a titration method

\footnotetext{
* Received: 17th Ocrober 1978 - accepted: 21st Decernber 1979.
}

for the determination of cyanide by use of coulometrically generated mercury (II) ions, which produce more accurate and reproducible results than do silver ions.

The method described in this paper is a modification of Przybylowicz's. A stationary silver wire coated with mercury is used as a generating electrode and a silver wire treated with sodium sulfide serves as an indicating electrode. Przybylowicz used a phosphate buffer solution of $\mathrm{pH} 9.2$ as a titration medium and worked with generating currents up to $50.95 \mathrm{~mA}$. In the present study, a pH 11 (phosphate-sodium hydroxide) buffer solution is needed to prevent loss of cyanide during titration. The typical generating current used for cyanide in cigarette smoke can be $0.3 \mathrm{~mA}$, and very dilute solutions of cyanide, in concentrations of $1 \times 10^{-6}$ to $1 \times 10^{-5} \mathrm{~g} \mathrm{CN}^{-}$, can be titrated. The use of dilute smoke solutions greatly extends the life of the generating electrode and minimizes interference from other smoke components. Initially, a Leeds and Northrup constant-current coulometer was used in developing the method. Since then, a constant-current coulometer with a continuously variable output of 0 to $2 \mathrm{~mA}$ was constructed for these determinations. A highimpedance potentiometer with a digital display and output terminals for a strip-chart recorder is incorporated into the instrument. These features eliminate the need for an external millivoltmeter. A strip-chart recorder connected to the output terminals allows a potentiometric titration curve to be drawn automatically during the titration.

The end point is located and cyanide microequivalents can be calculated from the microcoulombs generated. The calibrated chart speed provides a convenient way to determine generation time, from which the amount of mercury (II) ions consumed at the end point can be calculated.

The method is rapid and simple; it requires few reagents; it is semi-automatic and provides a direct measure of cyanide in aqueous solutions. 


\section{EXPERIMENTAL}

\section{Solutions and Reagents}

Sodium Hydroxide Solutions: A $0.1 \mathrm{M} \mathrm{NaOH}$ solution was prepared for use in the smoke scrubber flask, and a $1.0 \mathrm{M} \mathrm{NaOH}$ solution was prepared for use with $0.5 \mathrm{M}$ $\mathrm{Na}_{2} \mathrm{HPO}_{4}$ as a $\mathrm{pH} 11$ titration medium.

Disodium Hydrogen Phosphate Solution: A $0.5 \mathrm{M}$ $\mathrm{Na}_{2} \mathrm{HPO}_{4}$ solution was prepared by dissolving $134 \mathrm{~g}$ of $\mathrm{Na}_{2} \mathrm{HPO}_{4} \cdot 7 \mathrm{H}_{2} \mathrm{O}$ in 11 of $\mathrm{H}_{2} \mathrm{O}$.

Sodium Sulfide Solution: A $5 \%$ aqueous solution was prepared by dissolving $5 \mathrm{~g}$ of $\mathrm{Na}_{2} \mathrm{~S}$ in $95 \mathrm{ml}$ of distilled water. (This solution is used to treat the silver indicator electrode.)

Buffer Solution ( $p H$ 11): This solution was prepared by combining $176 \mathrm{ml}$ of $1.0 \mathrm{M} \mathrm{NaOH}$ and $824 \mathrm{ml}$ of $0.5 \mathrm{M}$ $\mathrm{Na}_{2} \mathrm{HPO}_{4}$ solution.

Aqueous Lead Acetate: A stock solution of $0.1 \mathrm{M}$ $\mathrm{Pb}\left(\mathrm{CH}_{3} \mathrm{COO}\right)_{2}$ was prepared and $1 \mathrm{ml}$ was diluted to $100 \mathrm{ml}$ with distilled water to make a $0.001 \mathrm{M}$ solution. This solution $(4 \mathrm{ml})$ was added to the titration solution to precipitate any soluble sulfide.

Mercury: Distilled mercury was used to coat the No. 14 silver-wire anode used for coulometric generation of mercury (II) ions.

\section{Equipment and Apparatus}

1. The instrument consisted of a constant-current coulometer with a continuously variable output current of 0 to $2 \mathrm{~mA}$ and a built-in potentiometer. Output terminals were provided for a strip-chart recorder.

2. A Hewlett-Packard strip-chart recorder (Model 7101B) was used to record the potentiometric titration curves.

3. The indicating electrodes consisted of a double-junction reference electrode (Orion No. 90-02-00) and a No. 14 silver wire.

4. The anode (generating electrode) consisted of a No. 14 spiral-wound silver wire (surface area $4.8 \mathrm{~cm}^{2}$ ) coated with mercury. The cathode was a No. 14 platinum wire isolated from the titration media by placement in a buffer solution ( $\mathrm{pH} 11$ ) contained in an $8 \mathrm{~cm} \times 1.1 \mathrm{~cm}$ inside diameter (I.D.) tube fitted with a fine-glass frit.

5. A special smoke scrubber flask (Figure 1) was used to collect the HCN from the cigarette smoke.

6. A single-port Phipps and Bird smoking machine (cat. No. 9900-300) was used for smoking of test cigarettes.

\section{Treatment and Care of the Electrodes}

The sensitivity of the silver-wire indicator electrode was considerably improved by immersing it in a $5 \%$ sodium sulfide solution for about $30 \mathrm{~s}$ before use. How often this treatment is needed was not determined, but no decrease in sensitivity was noticed after several titrations. (Caution: Sodium sulfide is toxic and liberates toxic $\mathrm{H}_{2} \mathrm{~S}$ gas in contact with acid. Appropriate precautions should be observed.) Because dilute smoke solutions were used, both the indicator and generator electrodes appeared to last indefinitely with proper treatment.

After a titration was completed, the electrodes were rinsed with distilled water. The generator electrode should be cleaned in concentrated ammonium hydroxide after 6 to 8 titrations. The generator electrode should also be coated with mercury about once or twice a week when in constant use.

\section{Procedure}

Two or more cigarettes were smoked at standard conditions (one $35 \mathrm{ml}, 2 \mathrm{~s}$ puff per $\mathrm{min}$ ) to a $23 \mathrm{~mm}$ butt or to within $3 \mathrm{~mm}$ of the overwrap, if they were filter cigarettes. During puffing, the whole smoke was scrubbed through $50 \mathrm{ml}$ of $0.1 \mathrm{M} \mathrm{NaOH}$ to collect the $\mathrm{HCN}$ (Figure 1). After smoking was completed, the contents of the scrubber

Figure 1. Schematic dlagram of smoke collection unit.

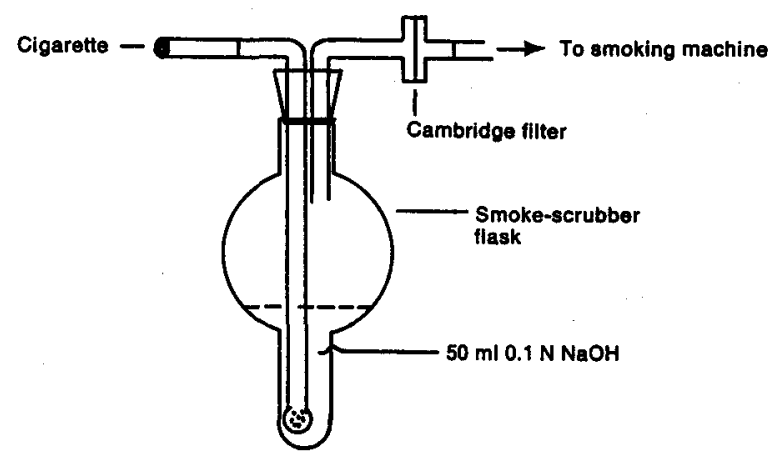

were transferred to a $100 \mathrm{ml}$ volumetric flask. The scrubber was rinsed twice with $20 \mathrm{ml}$ portions of $0.1 \mathrm{M} \mathrm{NaOH}$, which were also added to the flask. The $0.1 \mathrm{M} \mathrm{NaOH}$ solution was finally used to dilute the scrubber solution to the mark. A $5 \mathrm{ml}$ aliquot of sample was transferred to the titration cell (Figure 2), which contained $35 \mathrm{ml}$ of the $\mathrm{pH} 11$ buffer solution and $4 \mathrm{ml}$ of $0.001 \mathrm{M}$ lead acetate solution. The generator electrodes were connected to the coulometer, and the indicator electrodes were connected to the terminals of a potentiometer built into the instrument. The output of the potentiometer was connected to a Hewlett-Packard strip-chart recorder (Figure 3). The recorder was turned on and, when the pen was even with a chart line, the coulometer was started. The potentiometric titration was automatically recorded.

Figure 2. Schematic diagram of coulometric titration cell.

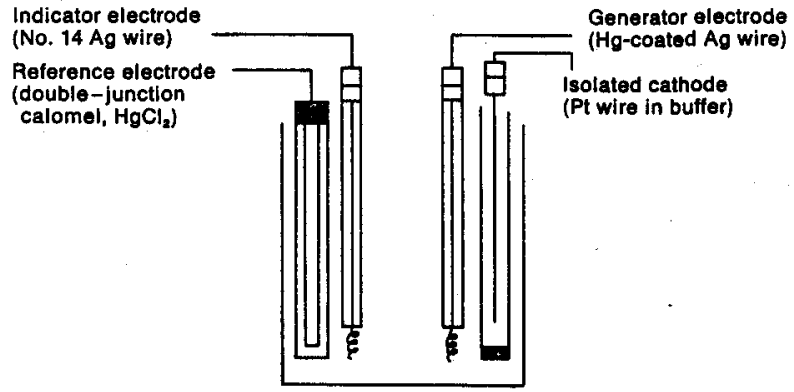


Flgure 3. Block dlagram of coulometric titration system.

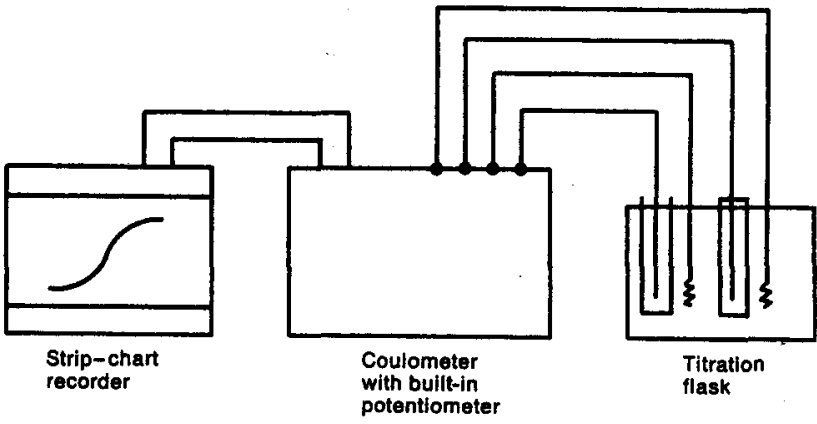

The end point was located by means of a plastic template with concentric arcs (Figure 4). This device consists of a transparent plastic square ( 6 in. square) containing concentric arcs of increasing radii originating at a hole ( $1 / 10$ in. diameter) in one corner of the square. The template was positioned over the potentiometric titration curve, and the best fitting arc was superimposed on each portion of the curve in turn. A point was then made through the hole in the template, and a line was drawn between the two points. The equivalence point was located where the line bisected the titration curve.

Flgure 4. Template with concentric arcs for determining ond point.

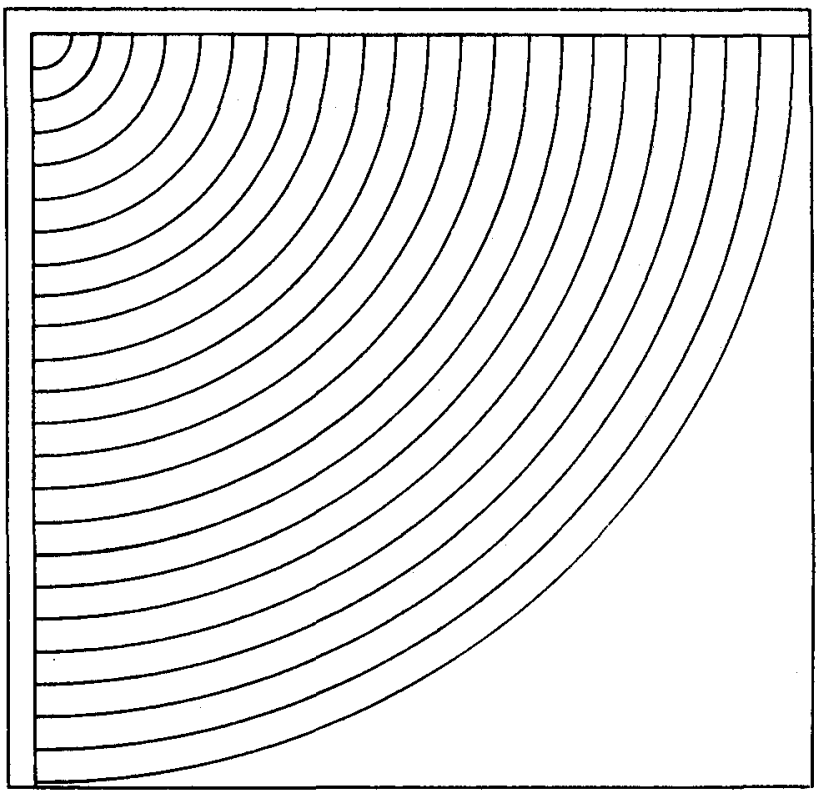

\section{Extraction and Analysis of Cyanide Trapped on Filters}

Cyanide trapped by the filters was extracted with $25 \mathrm{ml}$ of $0.1 \mathrm{M}$ sodium hydroxide. A 5 to $15 \mathrm{ml}$ aliquot of the extract was titrated coulometrically to determine the amount of cyanide. The cyanide delivered through the filter was collected in the basic aqueous scrubber previously described, and an aliquot was titrated.

\section{Calibration}

A known solution of sodium cyanide $\left(2 \times 10^{-3} \mathrm{M}\right)$ was titrated periodically to ensure that the instrument was operating properly.
Figure 5. Titration curve of known cyanide solution.

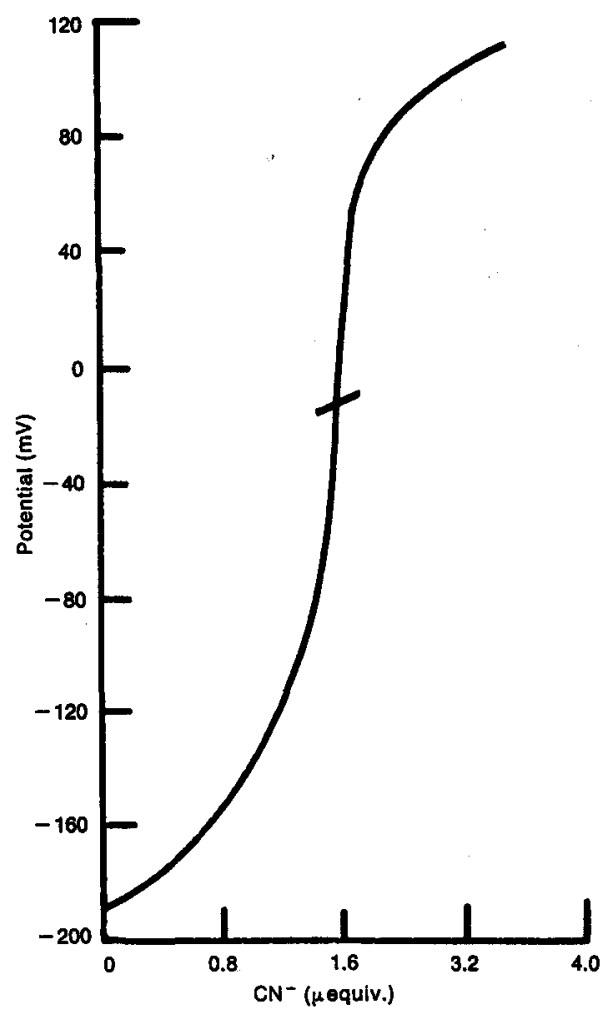

\section{RESULTS AND DISCUSSION}

Mercury (II) ions are generated and react as follows: $\mathrm{Hg}^{0} \rightleftharpoons \mathrm{Hg}^{+2}+2 \mathrm{e} ; \mathrm{Hg}^{+2}+2 \mathrm{CN}^{-} \rightleftharpoons \mathrm{Hg}(\mathrm{CN})_{2}$. Theoretically, one electron equivalent is displaced for each $\mathrm{CN}^{-}$. That the coulometric titration curve should correspond to a 1:1 reaction was confirmed experimentally by titration of a known cyanide solution. A typical potentiometric titration curve of $\mathrm{CN}^{-}$is shown in Figure 5. The micrograms of $\mathrm{CN}^{-}$are calculated from the following equation:

where

$$
\mu \mathrm{g} \mathrm{CN}^{-}=\frac{\mathrm{T} \times \mathrm{M} \times \mathrm{E} \times 1000}{96,487},
$$

$\mathrm{T}=$ time in seconds,

$\mathrm{M}=$ molecular weight of $\mathrm{CN}^{-}$,

$\mathrm{E}=$ milliamperes .

The relative standard deviation and average recovery of the coulometric titration of a known cyanide solution were $1.64 \%$ and $100.3 \%$ (Table 1). The results of $\mathrm{HCN}$ determinations on smoke from a filter cigarette by coulometric titration and by a spectrophotometric analysis were in good agreement and had about the same relative standard deviation, $5.31 \%$ by coulometric titration and $6.42 \%$ by spectrophotometric analysis (Table 2 ). [The spectrophotometric method was adapted to the analysis of cigarette smoke from a method published by Aldridge (7).]

Several cigarettes, including Kentudky $1 \mathrm{R} 1$ standard cigarettes, non-vented-filter cigarettes, non-filter cigarettes, vented-filter cigarettes, and European black-tobacco ciga- 
Table 1. Replicate titration of a known cyanide solution *.

\begin{tabular}{|c|c|}
\hline Run No. & $\mu$ equiv. found \\
\hline 1 & 3.30 \\
\hline 2 & 3.48 \\
\hline 3 & 3.40 \\
\hline 4 & 3.43 \\
\hline 5 & 3.40 \\
\hline 6 & 3.50 \\
\hline 7 & 3.38 \\
\hline 8 & 3.43 \\
\hline 9 & 3.38 \\
\hline 10 & 3.40 \\
\hline
\end{tabular}

- Theoretical, $3.40 \mu e q u i v$.; standard deviation, 0.055 ; relative standard deviation, $1.8 \%$; recovery, $100.3 \%$.

Table 2. Reproduclbility of coulometric and spectrophotometric methoda for HCN In the smoke of a fliter clgarette.

\begin{tabular}{l|c|c|c}
\hline Method & $\begin{array}{c}\mu g \text { HCN/cig. } \\
\text { (average) }\end{array}$ & $\begin{array}{c}\text { Standard } \\
\text { deviation }\end{array}$ & $\begin{array}{c}\text { Relative } \\
\text { standard } \\
\text { deviation } \\
(\%)\end{array}$ \\
\hline Coulometric & 270 & 14.3 & 5.31 \\
Spectrophotometric & 266 & 17.1 & 6.42 \\
\hline
\end{tabular}

- Ten determinations of two clgarettes per determination.

Table 3. Comparison of coulometrlc and spectrophotometric mothods.

\begin{tabular}{l|c|c}
\hline \multirow{2}{*}{ Cigarette } & \multicolumn{2}{|c}{$\mu g$ HCN/cigarette } \\
\cline { 2 - 3 } & $\begin{array}{c}\text { Coulometric } \\
\text { method }\end{array}$ & $\begin{array}{c}\text { Spectrophoto- } \\
\text { metric } \\
\text { method }\end{array}$ \\
\hline Fliter & 270 & 276 \\
Kentucky 1R1 (non-filter) & 376 & 379 \\
Molded-filter & 155 & 152 \\
Non-filter & 275 & 272 \\
Filter & 270 & 270 \\
Vented-filter & 89 & 92 \\
Black tobacco (filter) & 238 & 246 \\
Vented-filter (low-TPM *) & 25 & 30 \\
\hline
\end{tabular}

- total particulate matter

rettes, were analyzed by coulometric and spectrophotometric methods (7). The results are shown in Table 3.

The results obtained by the coulometric titration agreed

Figure 6. Effect of filter vents on HCN in clgarette smoke.

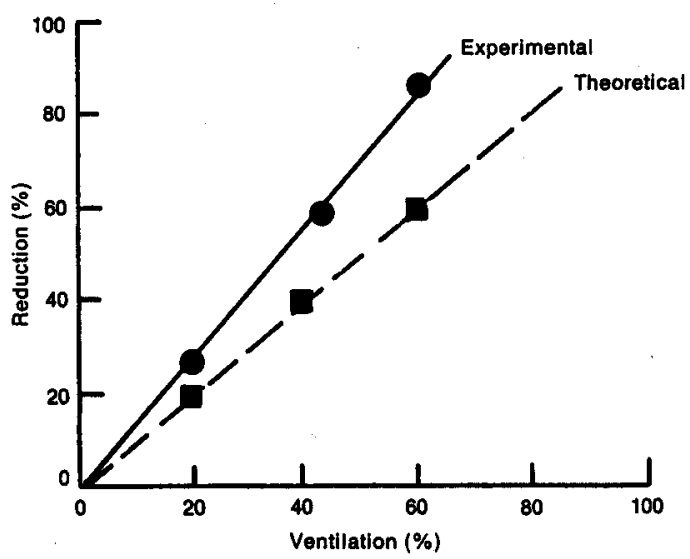

closely with the data obtained by the spectrophotometric method (7). Statistical treatment indicated that the data are not significantly different at the $95 \%$ confidence level. Since these original data were obtained, a new coulometer was constructed and the sensitivity of the indicator electrode was improved. The new instrument is more compact and easier to use than the older instrument. In the various cigarettes analyzed as shown in Table 3, the vented-filter cigarettes gave much lower amount of HCN than the others. Thus ventilation is an effective means of lowering the $\mathrm{HCN}$ content of cigarette smoke. Because of interest in vented-filter cigarettes, the effect of venting was examined more closely with filter cigarettes vented to provide 20,40 , and $60 \%$ smoke dilution. A non-vented-filter cigarette was used as a control. The vents were situated $12.5 \mathrm{~mm}$ from the mouth end of a $20 \mathrm{~mm}$ filter. The cigarettes were smoked to within $3 \mathrm{~mm}$ of the overwrap. The results indicate that $\mathrm{HCN}$ was reduced more than expected from ventilation alone (Figure 6). The filters with $20 \%$ ventilation reduced $\mathrm{HCN}$ content by $27 \%$, those with $40 \%$ ventilation reduced it by $58 \%$, and those with $60 \%$ ventilation reduced it by $86 \%$.

The vents may affect gas-phase HCN in the smoke by increasing diffusion through the cigarette wrap or by decreasing the smoke velocity and enabling removal of more of the particulate-phase HCN by the filter. To determine which mechanism was responsible for reducing the $\mathrm{HCN}$, additional vented cigarettes with 20,40 , and $60 \%$ ventilation were prepared and smoked. The cyanide delivered and the cyanide trapped by the filters were determined. The results (Figure 7) indicate that less $\mathrm{HCN}$ was trapped by the filters than was expected. The amount of $\mathrm{HCN}$ trapped on the non-vented filter was $54 \mu \mathrm{g}$. The reduction due to ventilation was expected to correspond to the percentage ventilation. However, as shown, lower amounts than theorized were found. These data indicate that in addition to effecting air dilution, diffusion is a dominant mechanism by which $\mathrm{HCN}$ is reduced in the smoke of vented-filter cigarettes. Similar results were obtained by Norman (8).

Flgure 7. Effect of vents on HCN retalned by an acetate

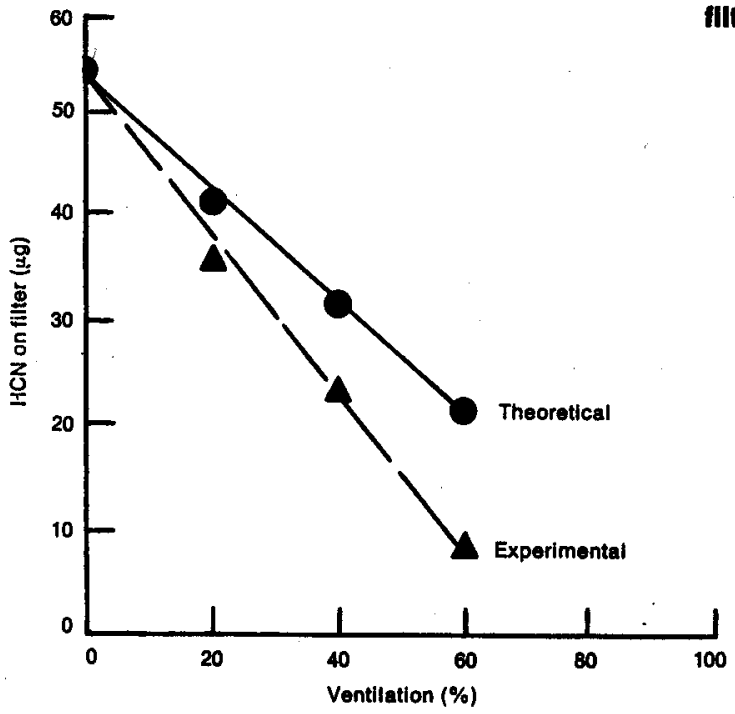




\section{SUMMARY}

We have described a method for determining the HCN delivered in whole cigarette smoke and in smoke condensate extracted from filters. The method is simple, rapid and precise. It eliminates many manual operations and is semi-automatic.

\section{ZUSAMMENFASSUNG}

Es wird über eine Methode zur Bestimmung von Cyanwasserstoff (HCN) im Gesamtrauch der Cigarette und in dem aus dem Filter extrahierten Kondensat berichtet. Das Verfahren ist einfach und arbeitet schnell und genau. Es ist halbautomatisch und macht viele manuelle Analysenschritte überflüssig.

\section{RESUME}

On décrit une méthode pour la détermination de l'acide cyanhydrique (HCN) dans la fumée totale de la cigarette et dans le condensat de fumée extrait du filtre. La méthode est simple, rapide et précise. Elle est semi-automatique et supprime plusieurs opérations manuelles.

\section{REFERENCES}

1. Mattina, C. F.: Tob. Sci. 16 (1972) 113-114.

2. Brunnemann, K. D., Louis $\mathrm{Yu}$ and D. Hoffmann: J. Anal. Toxicol. 1 (1977) 38-42.

3. Vidkroy, D. G., and George L. Gaunt, Jr.: Tob. Sci. 16 (1972) 22-25.

4. Reif, H.: Fachliche Mitteilungen der Austria Tabakwerke AG No. 13, 1972, 220-224.

5. Collins, P. F., N. M. Sarji and J. F. Williams: Tob. Sci. 14 (1970) 12-15.

6. Przybylowicz, E. P., and L. B. Rogers: Anal. Chem. 30 (1958) 65-68.

7. Aldridge, W. N.: Analyst 69 (1944) 262-265.

8. Norman, V.: Beitr. Tabakforsch. 7 (1974) 282-287.

Author's address:

Tennessee Eastman Company,

Researd Department,

Kingsport, Tennessee, 37662, U.S.A, 